\title{
Amphibians Diversity (Amphibia: Anura) at Hotel Tree of Life, Kandy
}

\author{
P. Perera*, T. Somarathne \\ Hotel Tree of Life, Yahalatenna, Kandy, Sri Lanka \\ *eme@hoteltreeoflife.com
}

\begin{abstract}
The Hotel Tree of Life is situated in a 26 ha land area at Barigama (7³1'84'N 8057'74'E) in Kandy district, central Province of Sri Lanka. This hotel was established in an old tea estate premises that was present about 100 years ago. During the last 100 years, upon abandoned, the tea estate had overgrown into a private owned secondary forest. The area now consists of a 25 ha forest that is owned and managed by the hotel.
\end{abstract}

The study was conducted from August 2014 to July 2015 in the hotel and the adjacent forest area. Visual encounter (assisted by the calls) sampling method was used during day and night sampling. Four species from the Critically Endangered (CR) Red Data category were again patch sampled for micro-habitat, by using quadrat $\left(1 \times 1 \mathrm{~m}^{2}\right)$. Minimal disturbance to habitat was considered a priority at all sampling locations. Different micro-habitats were sampled to obtain an overall diversity reading to find out the observable diversity of amphibians in the hotel. All sampled species were handled, using capture and released at the same location.

After having the quadrate sampling, it was found that one location had a diverse population of Pseudophilautus zorro known to be CR. One of the rare findings was the Pseudophilautus cf semiruber that was found in the hotel executive staff quarters. The species was rediscovered after 99 years in 2012 and known to be Data Deficient (DD).

19 species of amphibians from six families were found during the study (one species Lankanectus corrugatus is an endemic genus to Sri Lanka). From those identified, 14 species (74\%) are endemic and five are non-endemic (26\%). Family Bufonidae (Duttaphrynus melanostictus), Ranidae (Hylarana gracilis), Dicroglossidae (Ramanella obscura), Microhylidae (Zakerana keertisinghei, Z. syhadrensis, Hoplobatrachus crassus, Euphlyctis cyanophlyctis, E. hexadactylus), Nyctibatrachidae (Lankanectes corrugatus), Rhacophoridae (Polypedates cruciger, Pseudophilautus pleurotaenia, P. fergusonianus, $P$. cavirostris, $P$. zorro, $P$. semiruber, P. rus, $P$. popularis, $P$. hallidayi, $P$. schneideri) were found during the study. By considering these findings, the hotel can be considered as a potential amphibian hotspot. A general habitat enrichment program and awareness notices (biodiversity protected area) were placed in the area as a conservation measurement. Numerous waterholes were created in the location with up-cycled material, to enhance habitat diversity.

Keywords: Diversity, Amphibia, Anura, Conservation, Critically Endangered, Biodiversity protected area, Pseudophilautus 